\title{
Interaction between Soil Drouhgt and Allelopathic Factor on Wheat Seedlings Performance ${ }^{+}$
}

\author{
Nataliya P. Didyk*, Nadia V. Rositska, Bogdana O. Ivanytska (1) and Nataliya V. Zaimenko
}

Citation: Didyk, N.P.; Rositska, N.V.; Ivanytska, B.O.; Zaimenko, N.V. Interaction between Soil Drouhgt and Allelopathic Factor on Wheat Seedlings Performance. Biol. Life Sci. Forum 2021, 4, 59. https://doi.org/ 10.3390/IECPS2020-08732

Academic Editor: Yoselin

Benitez-Alfonso

Published: 1 December 2020

Publisher's Note: MDPI stays neutral with regard to jurisdictional claims in published maps and institutional affiliations.

Copyright: (c) 2020 by the authors. Licensee MDPI, Basel, Switzerland. This article is an open access article distributed under the terms and conditions of the Creative Commons Attribution (CC BY) license (https:// creativecommons.org/licenses/by/ $4.0 /)$.
M. M. Gryshko National Botanical Garden, National Academy of Sciences of Ukraine, Str. Timiryazevska 1, 01014 Kyiv, Ukraine; rositska.nadiia@gmail.com (N.V.R.); ivanytskabo@ukr.net (B.O.I.); zaimenkonv@ukr.net (N.V.Z.)

* Correspondence: nataliya_didyk@ukr.net; Tel.: +380-44-285-5453

+ Presented at the 1st International Electronic Conference on Plant Science, 1-15 December 2020; Available online: https:/ /iecps2020.sciforum.net/.

\begin{abstract}
The interaction between pre-sowing seed priming and soil drought on wheat physiological performance and allelopathic potential has been studied in alaboratory pot experiment. Amixture of cinnamic, salicylic and ascorbic acids $(0.01,0.1$ and $1 \mathrm{mM})$ was used as a priming agent. The soil moisture was regulated by watering pots to $20 \%, 40 \%$ and $60 \%$ of field capacity. The macronutrient content in the rhizosphere soil was also measured. The results obtained indicated that mild allelopathic stress applied to seeds made seedlings more resistant to subsequent drought stress and contributed to the increase of their allelopathic potential. Intensification of drought stress resulted in the decrease in production of allelopathic inhibitors in wheat plants and an increase of allelopathic stimulants and organic carbon in the rhizosphere soil. Changes in allelopathic activity of the rhizosphere soil closely correlate with the changes in organic carbon, nitrates, iron and phosphorus. While soil reaction, concentration of ammonia, manganese, potassium and sulfur displayed no correlation with soil allelopathic activity. The phenomena of cross-synergism and cross-antagonism between the interacting factors are discussed in this paper.
\end{abstract}

Keywords: allelochemicals; soil drought; seed priming; cross-adaptation; wheat

\section{Introduction}

Drought is the most challenging abiotic stress causing annual yield losses worldwide of about $17 \%$ [1]. In Ukraine, for the last 40 years, the notable increase in drought frequencies, especially during the spring, has led to an enhanced risk of death for susceptible plants in the early stages of ontogenesis. During the last two decades the frequency of droughts has nearly doubled. It is expected that further warming in Ukraine will lead to a sharp increase in the deficit of water in the soil in the spring and summer months. Furthermore, there recently appeared a dangerous tendency of droughts extending to the areas that used to belong to zones of sufficient humidity, such as Polissie and the northern forest-steppe [2].

Although selection and breeding is the ultimate way to produce stress tolerant crops, the exogenous application of phytoprotectans, boosting natural plant defense strategies, has been considered as a short-term solution to alleviate the adverse effects of different stresses on plants during the last decade. Phytoprotectants are various non-toxic substances mostly of natural origin that benefit plant's potential to adapt to various abiotic or biotic stressfactors. This is achieved by interacting with plant-signaling cascades and thereby reducing negative plant reactions to stress [3-5]. Plant secondary metabolites with antioxidant potential such as ascorbic acid, salicylic acid and some phenolics are promising. Being natural substances, they are safe for the environment and agricultural products $[4,6]$.

Ascorbic acid (AA) is a unique multifunctional compound. It is involved in the most important energy processes of plant cells such as photosynthesis and respiration. 
It is a potent antioxidant. Endogenic AA affects growth processes, flowering, and water balance, regulates activity of some enzymes associated with the metabolism of nucleic acid and protein synthesis, and participates in adaptive responses to various types of biotic and abiotic stresses [7]. Seed priming with exogenous ascorbic acids was shown to improve the seedling's growth and performance under various abiotic stresses including soil drought [6].

Salicylic acid (SA) is an endogenic phenolic acid involved in the signal induction of systemic acquired resistance inplants to infections and abiotic stress factors, as well as having antioxidant and prooxidant properties [8]. Endogenous SA affects various physiological processes such as transpiration, stomata movements, photosynthesis, nutrient uptake and the transport of ions, plant growth and development [9]. Exogenous SA can induce resistance in plants to abiotic and biotic stress factors such as drought, high and low temperature, salt and osmotic stress, toxic metals and phytopathogenes $[3,6,9,10]$.

Though the physiological and biochemical mechanisms of the protective effects of exogenous AA and SA are not fully elucidated yet, there is an opinion that their antioxidant potential and ability to modulate signaling cascades are the key factors contributing to this phenomenon.

Cinnamic acid (CA) is a phenolic acid occurring naturally in plants that has a low toxicity and a broad spectrum of biological activities. It regulates growth and development, and has antioxidant, antimutagenic and antimicrobial potential [11]. Phenolic acids are common plant allelochemicals with diverse modes of action. They are universally distributed in plants, especially in their decomposition products. Recent interest in phenolic compounds stem from their potential to protect against oxidative stress caused by many types of biotic and abiotic stressors. Exogenous phenolic acids enter through the plant cell membrane and change the activity and function of certain enzymes and plant hormones. At low concentrations exogenic phenolic acids may stimulate plant defense systems. However, in high concentrations they increase lipid peroxidation and inhibit nutrient and water absorption leading to the slowing of plant growth [11].

Studies of mixtures of phenolic compounds have shown that individual components can be additive when being evaluated for their combined effects [11]. Our previous studies showed that the combined application of AA, SA and CA displayed synergistic effects towards plant growth parameters under drought conditions [6].

Seed priming is a pre-sowing treatment used to improve the rate and uniformity of germination, as well as improve the seedlings' vigor and stress resistance. Numerous studies have shown that the effectiveness of a certain priming technique can vary significantly depending on the crop species and cultivars. In fact, to optimize the priming method for a concrete crop variety, one needs to take into account not only it's taxonomical position but also the impact of particular environmental conditions [12].

The objective of the present study was to assess the interaction between pre-sowing seed priming, with the mixture of organic acids mentioned above, and soil drought intensity on the physiological processes and allelopathic potential of wheat seedlings, as well as the allelopathic and nutritional regime of the rhizosphere soil in the factorial pot experiment.

\section{Experiments}

\subsection{Seed Materials}

A factorial experiment was performed using wheat (Triticum aestivum L., cv. "Pereyaslavka") as a testplant. Wheat is considered the first strategic food crop in Ukraine. It is the basic staple food for bread making. The wheat seeds were surface-sterilized with a $5 \%$ sodium hypochlorite solution for five minutes and washed thoroughly with sterilized tap water.

\subsection{Experimental Setup and Cultivation Conditions}

The experiment was conducted in the laboratory conditions at the Department of Allelopathy, M.M. Gryshko National Botanical Garden (Kyiv, Ukraine). Polyethylene 
containers (10 $\mathrm{cm}$ internal diameter) were filled with $0.5 \mathrm{~kg}$ of gray podzol soil sterilized in an oven at $100{ }^{\circ} \mathrm{C}$ for two hours, air-dried and sieved (through a $2 \mathrm{~mm}$ sieve). The wheat seeds were presoaked in Petri dishes each containing $5 \mathrm{~mL}$ of the aqueous solution of AA, SA and CA (1:1:1) in one of the following concentrations of $0.01 ; 0.1 ; 1 \mathrm{mM}$ or distilled water (control) for three hours and sown in these pots. The experiment included three levels of soil moisture: $20 \%, 40 \%$ and $60 \%$ of field capacity (FC). The moisture level was maintained by a gravimetric method till the end of the experiment. Testplants were cultivated for 28 days at $22-30{ }^{\circ} \mathrm{C}$ temperature, natural sunlight and $60-75 \%$ relative humidity. The experimental design was two factorial $(3 \times 3)$, arranged in a completely randomized design with five replications.

\subsection{Measurements}

The number of germinated seeds was counted on 3-7 days after sowing. Root and shoot length and seedling dry biomass were recorded at the end of the experiments. The characteristics of water balance (relative water content (RWC) and water deficit (WD) in the foliar tissues) were measured by a gravimetric method [13] two weeks after germination and at the end of the experiment. The content of flavonoids and catalase activity were determined before harvesting. Catalase activity (CAT) was determined by the method [14]. Flavonoids were extracted with $70 \%$ ethanol, their quantitative content was determined using a qualitative reaction with $\mathrm{AlCl}_{3}$ spectrophotometrically [15]. Allelopathic activity of the rhizosphere soil was assessed by direct bioassay [16] on cress (Lepidium sativum L.) root growth. The same gray podzol soil in which testplants were not cultivated was used as a control. Allelochemicals from dried shoots and roots were extracted with distilled water ( $2 \mathrm{~g}$ per $100 \mathrm{~mL}$ ) and their biological activity was assessed using bioassay on cress root growth [17]. As the control we used distilled water. The contents of macronutrients in the rhizosphere soil were determined by a colorimetric method [18].

\subsection{Statistical Analysis}

A two-way general linear model analysis of variance (ANOVA) was used to compare the significant effects of the treatment (mixture concentration), the soil moisture level and their interaction (treatment + soil moisture level) on biometrical and physiological parameters of the wheat seedlings, allelopathic activity, and nutrient availability in the rhizosphere soil. The data presented in the tables are grouped by weighted means. All the replicates were analyzed together with experimental repeats. Levene's test was used to check the homogeneity of variances. The individual treatment means were compared using the LSD (least significant difference) test, with a significant level at $p \leq 0.05$. The interaction between pre-sowing seed priming and soil drought was assessed using the coefficient of interactive effect. The latter was counted as the difference between empirical data on the combined effect of the above-mentioned factors with the theoretically calculated sum of the impacts of the isolated factors [19]. In the case of the co-efficient of interactive effect $(\mathrm{CIE})>0$, we assume a cross-synergism, otherwise $(\mathrm{CIE}<0)$ we assume a cross-antagonism. The reliability of the CIE was estimated by the error of the co-efficient of interactive effect (CIE error) calculated as the root of the sum of the squares of the effects of factors acting alone and in combination [19]. In the case of [CIE] < CIE error, we assumed independent effect [19].

We also used factor analysis (principal components method) to distinguish the characteristics of the rhizosphere soil which displayed the highest sensitivity to the environmental factors. All statistical tests were performed using Statistica 10.0 and Microsoft Office Excel 2007 software.

\section{Results}

The results obtained showed that both of the studied factors (seed priming and soil moisture) significantly affected the testplants' growth and performance $(p<0.05)$. The 
characteristics of water deficit and flavonoid content in the leaves of wheat seedlings were the most sensitive to the combination of studied factors (Table 1).

Table 1. Analysis of variance of the effects of priming mixture concentration (PM) and soil moisture on wheat seeds germination and seedling performance.

\begin{tabular}{|c|c|c|c|c|c|c|c|c|c|c|}
\hline \multirow{2}{*}{$\begin{array}{c}\text { Soil } \\
\text { Moisture, } \\
\%\end{array}$} & \multirow{2}{*}{$\begin{array}{c}\text { PM Concent- } \\
\text { Ration, } \\
\text { M }\end{array}$} & \multirow{2}{*}{$\begin{array}{l}\text { Germi- } \\
\text { Nation, } \\
\% \\
\end{array}$} & \multirow{2}{*}{$\begin{array}{c}\text { Shoot } \\
\text { Height, } \\
\text { mm }\end{array}$} & \multirow{2}{*}{$\begin{array}{c}\text { Leaf } \\
\text { Area, } \mathrm{cm}^{2}\end{array}$} & \multicolumn{2}{|c|}{ D. w., mg } & \multirow{2}{*}{ RWC, \% } & \multirow[b]{2}{*}{ WD, \% } & \multirow{2}{*}{$\begin{array}{c}\mathrm{CA}, \mathrm{mM} \\
\mathrm{H}_{2} \mathrm{O}_{2} / \mathrm{min} \times \mathrm{g} \\
\text { d.w. }\end{array}$} & \multirow{2}{*}{$\begin{array}{c}\text { Flavo- } \\
\text { Noids, \% } \\
\text { to d.w. }\end{array}$} \\
\hline & & & & & Roots & Shoots & & & & \\
\hline 20 & 0 & 50.1 & 119.8 & 2.9 & 3.4 & 6 & 80.1 & 23.1 & 7.5 & 0.51 \\
\hline 20 & $10^{-5}$ & 53.2 & 148.8 & 4.5 & 8.4 & 7.2 & 85.4 & 15.2 & 9.6 & 0.67 \\
\hline 20 & $10^{-4}$ & 67.1 & 153.1 & 4.7 & 8.5 & 7.9 & 89.2 & 9.3 & 9.6 & 0.78 \\
\hline 20 & $10^{-3}$ & 67.1 & 152.1 & 4.8 & 8.5 & 7.3 & 87.3 & 11.1 & 8.9 & 0.86 \\
\hline 40 & 0 & 60.3 & 194.2 & 7.8 & 7.6 & 9.3 & 91.2 & 7.3 & 8.3 & 0.79 \\
\hline 40 & $10^{-5}$ & 73.2 & 197.6 & 8.2 & 7.3 & 14.6 & 92.5 & 3.2 & 7.2 & 1.07 \\
\hline 40 & $10^{-4}$ & 75.3 & 209.4 & 7.8 & 8.6 & 14.9 & 91.7 & 4.1 & 7.8 & 0.89 \\
\hline 40 & $10^{-3}$ & 72.6 & 220.3 & 8.4 & 7.6 & 14.5 & 91.9 & 1.6 & 7.5 & 0.97 \\
\hline 60 & 0 & 72.5 & 210.1 & 7.9 & 6.3 & 13.1 & 91.6 & 3.1 & 5.5 & 0.68 \\
\hline 60 & $10^{-5}$ & 78.4 & 216.3 & 8.8 & 8.4 & 13.9 & 91.7 & 2.1 & 5.3 & 0.75 \\
\hline 60 & $10^{-4}$ & 80.1 & 203.8 & 7.9 & 7.4 & 17.5 & 91.6 & 1.9 & 5.5 & 0.73 \\
\hline 60 & $10^{-3}$ & 75.1 & 203.2 & 7.8 & 7.3 & 18.1 & 91.8 & 2.8 & 6.2 & 0.74 \\
\hline$L S D$ & & 1.1 & 4.1 & 0.3 & 5.9 & 6.8 & 1.4 & 6.1 & 0.8 & 0.1 \\
\hline $\mathrm{F}_{1}$ & & 2.47 & 2.36 & 3.23 & 2.42 & 2.24 & 2.70 & 8.50 & 2.70 & 16.95 \\
\hline$P_{1}$ & & 0.05 & 0.08 & 0.03 & 0.05 & 0.07 & 0.03 & 0.00 & 0.03 & 0.00 \\
\hline $\mathrm{F}_{2}$ & & 2.90 & 4.80 & 5.55 & 2.63 & 4.68 & 5.52 & 17.21 & 3.10 & 20.77 \\
\hline $\mathrm{P}_{2}$ & & 0.07 & 0.01 & 0.01 & 0.08 & 0.01 & 0.01 & 0.00 & 0.06 & 0.00 \\
\hline
\end{tabular}

${ }_{1}$-values of $\mathrm{F}$ and $\mathrm{P}$ for concentration of priming mixture as a categorical predictor, 2 - values of $\mathrm{F}$ and $\mathrm{P}$ for soil moisture as a categorical predictor, LSD—least significant difference, F-Fisher's test, $\mathrm{P}$ —significance level.

Moderate (40\% FC) drought stress inhibited seed germination and the growth of shoots, but stimulated the development of the root system and accumulation of protective antioxidants (flavonoids, catalase) in the wheat seedlings. Under severe drought ( $20 \% \mathrm{FC})$, all registered characteristics of wheat growth and development, as well as biosynthesis of protective substances declined sharply. It could be concluded that wheat seedlings were subjected to physiological stress at $40 \% \mathrm{FC}$ and displayed significant inhibition of growth and metabolic processes at $20 \%$ FC.

Pre-sowing priming of wheat seeds with a mixture of AA, SA and CA significantly stimulated seed germination, biomass accumulation by shoots and roots of wheat seedlings and improved characteristics of water balance in the leaves under moderate and severe soil drought. Among the studied physiological characteristics, catalase activity and flavonoid content were the most sensitive to the impact of the pre-sowing seed priming. The size of the protective effect of priming on the studied physiological characteristics of wheat seedlings positively correlated with the intensity of soil drought.

Water soluble allelochemicals extracted from shoots and roots of wheat seedlings displayed an inhibitory effect on cress root growth (Table 2). Whereas the rhizosphere soil showed a stimulative effect in the same bioassay. As soil moisture increased, the inhibitory effect of water extracts from wheat seedling shoots and roots increased as well. The opposite tendency was observed for the stimulative activity of the rhizosphere soil.

Analysis of variance showed that both soil moisture and seed priming significantly $(p<0.05)$ affected the allelopathic activity of water extracts from roots and shoots of wheat seedlings as well as the content of allelochemicals and organic carbon in the rhizosphere soil. Moisture levels also significantly affected the content of iron ions and nitrates in the rhizosphere soil (Table 2). 
Table 2. Analysis of variance of the effects of the priming mixture concentration and soil moisture on the allelopathic activity of wheat seedlings and rhizosphere soil as well as on some agrochemical characteristics of the latter.

\begin{tabular}{|c|c|c|c|c|c|c|c|c|c|c|c|c|c|c|c|}
\hline \multirow{3}{*}{$\begin{array}{c}\text { Soil } \\
\text { Moisture, } \\
\%\end{array}$} & \multirow{3}{*}{$\begin{array}{l}\text { PM Con- } \\
\text { centration, } \\
\text { M }\end{array}$} & \multicolumn{3}{|c|}{$\begin{array}{l}\text { Allelopathic Activity, } \\
\% \text { to Control }\end{array}$} & \multicolumn{11}{|c|}{ Soil pH, Carbon (\%) and Macronutrients, $\mathrm{mg} / \mathrm{L}$} \\
\hline & & \multicolumn{2}{|c|}{ Water Extracts } & \multirow{2}{*}{ Soil } & \multirow{2}{*}{$C, \%$} & \multirow{2}{*}{$\mathrm{pH}$} & \multirow{2}{*}{ Mn } & \multirow{2}{*}{$\mathbf{S}$} & \multirow{2}{*}{$\mathrm{Fe}$} & \multirow{2}{*}{$\mathrm{Mg}$} & \multirow{2}{*}{$\mathrm{Ca}$} & \multirow{2}{*}{$\mathbf{K}$} & \multirow{2}{*}{$\mathbf{P}$} & \multirow{2}{*}{$\mathrm{NO}_{3}$} & \multirow{2}{*}{$\mathrm{NH}_{4}$} \\
\hline & & Roots & Shoots & & & & & & & & & & & & \\
\hline 20 & 0 & 93.6 & 93.6 & 158 & 6.2 & 7.7 & 100 & 200 & 1250 & 132 & 6236 & 214.5 & 164 & 23 & 7.7 \\
\hline 20 & $10^{-5}$ & 88.0 & 49.6 & 127 & 6.2 & 7.7 & 100 & 200 & 1250 & 132 & 6331 & 205.2 & 164 & 15 & 10 \\
\hline 20 & $10^{-4}$ & 88.7 & 48.0 & 122 & 6.6 & 7.8 & 110 & 200 & 1150 & 132 & 6831 & 205.2 & 164 & 15 & 7.7 \\
\hline 20 & $10^{-3}$ & 80.7 & 48.0 & 128 & 6.2 & 7.8 & 100 & 200 & 1150 & 132 & 5664 & 205.2 & 164 & 15 & 10 \\
\hline 40 & 0 & 64.5 & 60.1 & 112 & 3.9 & 7.8 & 100 & 200 & 1250 & 142 & 5998 & 223.8 & 109 & 18 & 10 \\
\hline 40 & $10^{-5}$ & 60.8 & 56.4 & 117 & 3.6 & 7.7 & 100 & 200 & 1250 & 132 & 5664 & 223.8 & 109 & 9.5 & 10 \\
\hline 40 & $10^{-4}$ & 61.2 & 54.7 & 113 & 3.9 & 7.8 & 100 & 200 & 1150 & 132 & 5831 & 224.5 & 112 & 11 & 10 \\
\hline 40 & $10^{-3}$ & 60.2 & 51.8 & 114 & 4.2 & 7.7 & 100 & 200 & 1200 & 122 & 5998 & 223.8 & 109 & 11 & 8.2 \\
\hline 60 & 0 & 64.3 & 63.1 & 110 & 3.2 & 7.8 & 100 & 200 & 1000 & 131 & 5664 & 186.6 & 109 & 18 & 10 \\
\hline 60 & $10^{-5}$ & 63.2 & 55.7 & 97 & 2.6 & 7.6 & 80 & 200 & 750 & 122 & 5664 & 214.5 & 109 & 8.5 & 7.9 \\
\hline 60 & $10^{-4}$ & 62.3 & 49.8 & 93 & 2.1 & 7.7 & 80 & 200 & 750 & 132 & 6164 & 223.8 & 110 & 7.5 & 7.9 \\
\hline 60 & $10^{-3}$ & 58.5 & 45.8 & 94 & 2.6 & 7.7 & 120 & 200 & 750 & 131 & 6831 & 214.5 & 109 & 8.0 & 10 \\
\hline LSD & & 2.2 & 2.3 & 2.6 & 0.1 & 0.1 & 8.9 & 8.3 & 6.9 & 4.4 & 4.4 & 7.2 & 3.8 & 2.2 & 0.8 \\
\hline $\mathrm{F}_{1}$ & & 3.5 & 2.31 & 3.32 & 1.5 & 0.1 & 1.7 & 0.9 & 0.24 & 4.1 & 2.78 & 0.08 & 0.6 & 4.6 & 0.9 \\
\hline$P_{1}$ & & 0.02 & 0.10 & 0.02 & 0.2 & 1.0 & 0.2 & 0.5 & 0.86 & 0.1 & 0.08 & 0.96 & 0.61 & 0.1 & 0.5 \\
\hline $\mathrm{F}_{2}$ & & 19.8 & 0.38 & 42.7 & 34 & 0.2 & 1.5 & 0.6 & 0.18 & 0.2 & 0.08 & 0.21 & 0.84 & 8.6 & 0.8 \\
\hline $\mathrm{P}_{2}$ & & 0.00 & 0.68 & 0.00 & 0.0 & 0.9 & 0.2 & 0.7 & 0.88 & 0.9 & 0.98 & 0.89 & 0.5 & 0.1 & 0.5 \\
\hline
\end{tabular}

1 - values of $\mathrm{F}$ and $\mathrm{P}$ for concentration of priming mixture as a categorical predictor, 2 - values of $\mathrm{F}$ and $\mathrm{P}$ for soil moisture as a categorical predictor, LSD—least significant difference, F-Fisher's test, $\mathrm{P}$-significance level.

Analysis of the interactive effect of pre-sowing seed priming and soil drought on allelopathic activity of the rhizosphere soil and water extracts from roots of wheat seedlings showed cross-synergism ( $\mathrm{C}_{\mathrm{IE}}=26.7$ and 21.4, respectively). However, the interactive effect of pre-sowing seed priming and soil drought on the allelopathic activity of the water extracts from shoots of wheat seedlings was negative $\left(C_{\mathrm{IE}}=-41.7\right)$, so we assumed a cross-antagonism.

The analysis of the distribution of macronutrients in the rhizosphere soil under wheat seedlings showed that the content of organic carbon $(\mathrm{C} \%)$, iron, phosphorus and nitrates inversely depended on the level of soil moisture (Figure 1). The content of manganese, sulfur, potassium and calcium in the soil under the test plants did not display any significant dependence on the moisture level.

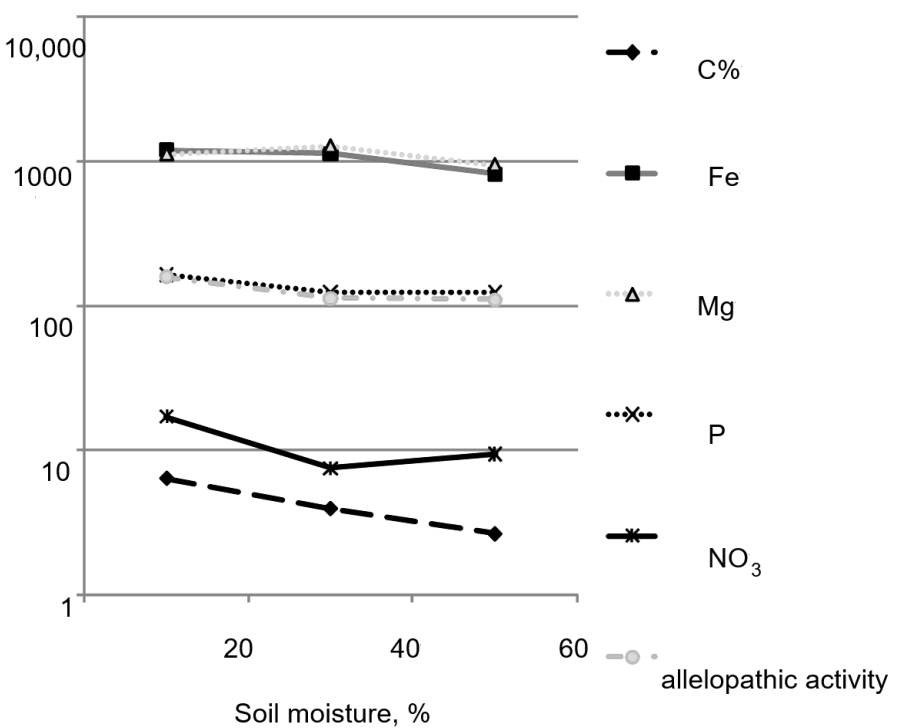

Figure 1. The dependence of content of some macronutrients $(\mathrm{mg})$, organic carbon $(\mathrm{C} \%)$ as well as allelopathic activity of the rhizosphere soil of wheat seedlings on soil moisture level. 
Correlation analysis showed that the allelopathic activity of the rhizosphere soil positively correlated with the content of organic carbon $(R=0.87)$, iron $(R=0.73)$, phosphorus $(\mathrm{R}=0.42)$ and nitrates $(\mathrm{R}=0.74)$.

Factor analysis (principal components method) of the studied characteristics of the rhizosphere soil showed that the allelopathic activity and concentrations of organic carbon, nitrates and magnium ions are the most sensitive to environmental changes (Figure 2). Changes in allelopathic activity of the rhizosphere soil closely correlated with changes in organic carbon, nitrates, iron and phosphorus. The rest of the studied macronutrients as well soil reaction showed no such correlation. This conclusion is in good agreement with the ANOVA results (see Table 2).

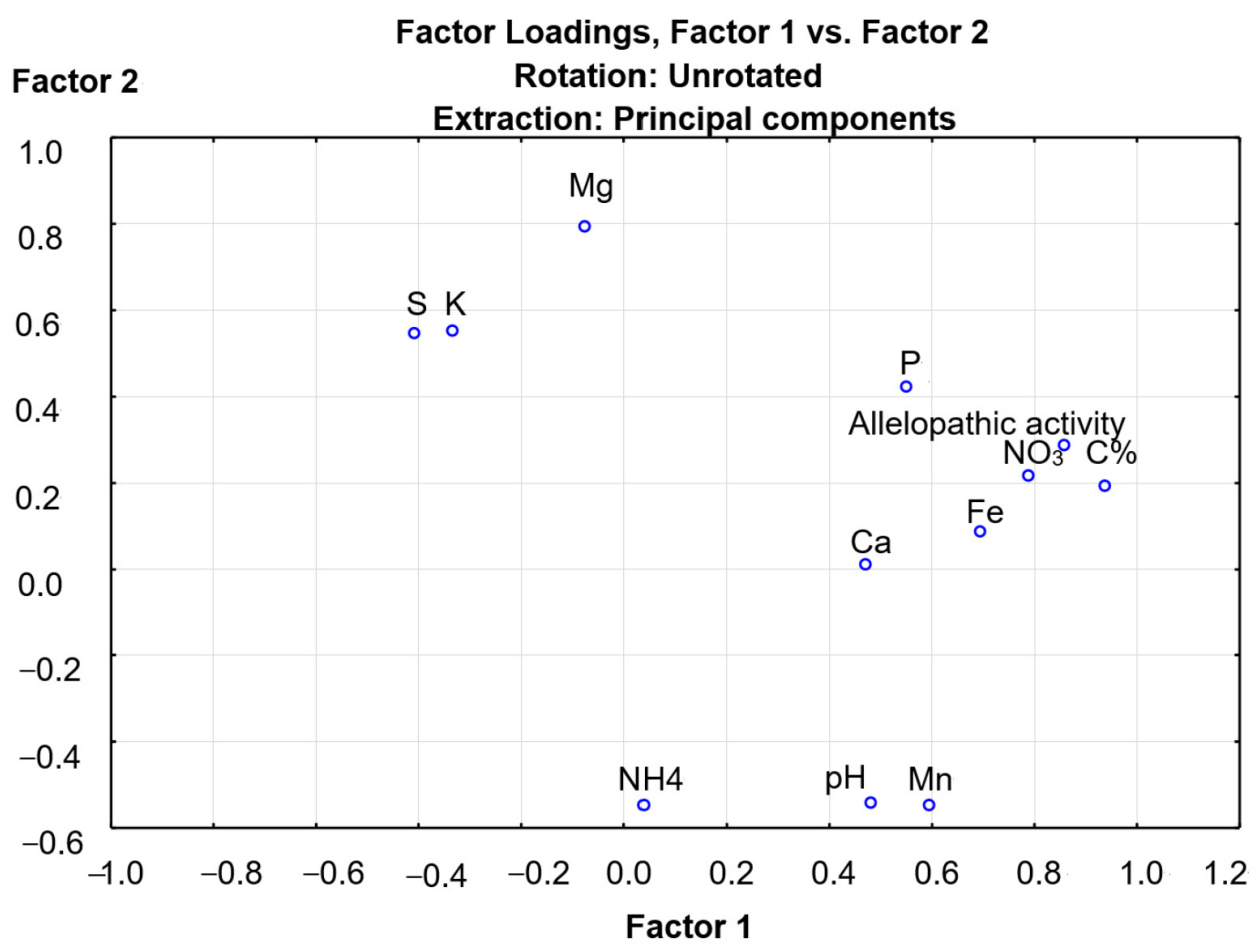

Figure 2. Factor analysis of the rhizosphere soil characteristics.

\section{Discussion}

Summarizing the data obtained in this study as well as the results of other works $[3,4,6]$ published on the problem of interaction between allelopathy and abiotic stress factors, it can be concluded that a short and mild exposure to allelopathic stress (in our study it was simulated by wheat seed pre-sowing priming with millimolar concentrations of AA, SA and CA) may mitigate the adverse effects of a subsequent abiotic stress (i.e., soil drought). This phenomenon is referred to as a cross-adaptation. Despite the considerable interest of modern phytophysiologists in the phenomena of cross-adaptation, cross-synergism, and cross-antagonism, their physiological mechanisms are still practically unclear. It is believed that cross-adaptation is based on non-specific adaptive reactions, playing an important role in the induction of protective antioxidant systems [20-22]. It is known that exogenous phenolic acids can cause oxidative damage through enhanced generation of ROS, leading to the increase in the activities of antioxidant defense systems and the induction of signaling cascades $[23,24]$. In phytotoxic concentrations, exogenic phenolic acids could have similar effectsin testplants as in water stress [23,25].

In our study, pre-sowing priming of wheat seeds with millimolar concentrations of AA, SA and CA induced nonspecific defense mechanisms (increased catalase activity, flavonoid content, changes in the shoot/root ratio) which contributed to the observed increased resistance to the subsequent soil drought. On the other hand, seed priming 
stimulated an accumulation of allelopathic inhibitors in shoots and roots of the wheat seedlings (cross-synergism).

In our experiment the effect size of seed priming positively correlated with the intensity of soil drought. This tendency is in good agreement with the findings of other authors stating that the intensification of stress conditions enhances the physiological activity of phenolic acids intestplants [25]. It is known that climatic and edaphic factors (ultraviolet (UV) radiation, low / high temperature, ozone, heavy metals, drought, availability of nutrient ions etc.) may play a significant role in accumulating allelochemicals or their breakdown products to bioactive levels $[3,4,6,26]$. Nevertheless, till now the issue of the interaction between the allelopathic factor and environmental stresses have been given little consideration.

Soil drought stimulated the excretion of allelochemicals with stimulative activity into the rhizosphere soil by wheat seedlings. On the other hand, drought inhibited the accumulation of phytotoxic allelochemicals in living organs (shoots and roots) of wheat seedlings. This led to the amelioration of the allelopathic conditions of soil surrounding the seedling's roots, which could contribute to enhanced vitality of wheat seedlings under stressful conditions (cross-adaptation).

Winter wheat is known for its high allelopathic potential due to the presence of hydroxamic and phenolic acids in its exudations [27]. This trait allows this crop to reduce the seed bank of weeds in the soil and minimize the necessity of herbicides. The results obtained in our study demonstrate that abiotic (drought) and biotic (allelochemicals) factors in the environment could significantly modify intrapopulation allelopathic interactions between wheat plants, as well as their effects on weeds.

Apart from the direct effect of soil moisture on crop physiological processes, this factor also alters the soil microbial population, mineralization processes, redox reaction and absorptive properties [28]. In our study, as soil drought intensified, the content of organic carbon, iron, phosphorus and nitrates increased. This tendency correlated with the stimulative activity of the rhizosphere soil. In contrast, the content of ammonia, magnesium, manganese, sulfur, potassium and calcium in the rhizosphere soil of testplants did not show any significant dependence on the level of soil moisture. Obviously, this is due to the differences in the mobility of the nutrients in the soil, which are more readily taken up by plants with optimal water supply.

Many allelochemicals, particularly organic acids and phenolics etc. were shown to interact with soil nutrients, immobilizing them or increasing their availability to plants. For example, phenolic acids (p-coumaric, ferulic, p-hydroxybenzoic, protocatechuic etc.) were shown to influence the accumulation of soil organic $\mathrm{N}$ and inorganic ions such as $\mathrm{Al}, \mathrm{Fe}, \mathrm{Mn}$, and $\mathrm{PO}_{4}$ [29]. On the other hand, nutrient ions such as $\mathrm{Mn}, \mathrm{Fe}, \mathrm{Al}$ could form complexes with phenolic allelochemicals thus modulating their effect on plants [29]. The effect of allelochemicals on nutrient dynamics may ultimately affect the growth of plants in the community. Though such an effect could contribute significantly to the overall allelopathic effects within a plant community, the interaction between these two mentioned factors is rather poorly studied till now. Further studies are needed to elucidate the relationship between abiotic factors and allelochemicals for understanding the actual modes of action of allelopathic factors in the agricultural and natural ecosystems.

According to the results of our study, changes in allelopathic activity of the rhizosphere soil closely correlates with changes in organic carbon, nitrates, iron and phosphorus. While soil reaction and concentrations of ammonia, manganese, potassium and sulfur displayed no correlation with soil allelopathic activity. Further studies are needed to elucidate the relationship between macronutrients and the allelopathic regime of the rhizosphere soil.

The results of our study also demonstrate that wheat seedlings could modify the allelopathic and nutritional regime in the soil surrounding their roots in response to presowing seed priming and drought stress, suggesting that wheat seedlings could directly influence the magnitude of effects of the studied factors through feedback regulation. Such information will open new possibilities for a deliberate and predictable approach 
for improvements to the current agricultural practices in response to the predicted global climatechanges and the growing food requirement of the world's population.

\section{Conclusions}

In summary, the present study demonstrated the complicated interactions between allelopathy and soil drought on physiological and allelopathic characteristics of the target plants. A mild allelopathic stress applied to seeds made seedlings more resistant to subsequent drought stress and contributed to the increase of their allelopathic potential. Intensification of drought stress resulted in the decreased production of allelopathic inhibitors in the tissues of wheat seedlings and the enhancement of concentrations allelopathic stimulants and organic carbon in the rhizosphere soil. Changes in allelopathic activity inthe rhizosphere soil closely correlated with the changes in organic carbon, nitrates, iron and phosphorus. Soil reaction and concentrations of ammonia, manganese, potassium and sulfur displayed no correlation with soil allelopathic activity.

Thus, wheat seedlings showed their ability to modify the allelopathic and nutritional regime in the soil surrounding their roots in response to pre-sowing seed priming and drought stress which allowed them to change their immediate environment conditions to be more favorable for their further growth and development. Our findings give additional evidence that the ecological role of allelochemicals is more versatile than it is commonly believed (i.e., limited to intraspecific or interspecific competition or defense against pests and pathogens). It is a great challenge for future studies to assess the real role of allelochemicals in the adaptation of plant communities to stressful environmental factors at the ecosystem level.

Author Contributions: N.P.D. conceived and designed the experiments, analyzed the data; N.V.R. and B.O.I. performed the experiments; N.P.D. and N.V.Z. wrote the paper. All authors have read and agreed to the published version of the manuscript.

Institutional Review Board Statement: Not applicable.

Informed Consent Statement: Not applicable.

\section{Abbreviations}

The following abbreviations are used in this manuscript:

$\begin{array}{ll}\text { AA } & \text { Ascorbic acid } \\ \text { CA } & \text { Cinnamic acid } \\ \text { SA } & \text { Salicylic acid } \\ \text { CAT } & \text { Catalase activity } \\ \text { RWC } & \text { relative water content } \\ \text { WD } & \text { water deficit } \\ \text { d.w. } & \text { dry weight } \\ \text { PM } & \text { priming mixture } \\ \text { C\% } & \text { organic carbon } \\ \text { ANOVA } & \text { analysis of variance } \\ \text { LSD } & \text { least significant difference }\end{array}$

\section{References}

1. Rehman, S.; Harris, P.J.C.; Ashraf, M. Stress environments and their impact on crop production. In Abiotic Stresses: Plant Resistance through Breeding and Molecular Approaches; Ashraf, M., Harris, P.J.C., Eds.; Haworth Press: New York, NY, USA, 2005 ; pp. 3-18.

2. Vyshnivskiy, P.S. Multiplicity of manifestation of adverse weather conditions in the forest steppe zone in growing oilseeds cabbage. In Proceedings of the National Scientific Center "Institute of Agriculture NAAS"; Tvory: Kyiv, Ukraine, 2013 ; pp. 102-108.

3. Didyk, N.P.; Blum, O.B. Natural antioxidants of plant origin against ozone damage of sensitive crops. ActaPhysiol. Plant. 2011, 33, 25-34. [CrossRef]

4. Didyk, N.P.; Rositska, N.V.; Berebenchuk, L.D. The effect of rutin, ascorbic and salicylic acids on the functional state of wheat plants under drought conditions. Physiol. Biochem. Cultiv. Plants 2011, 43, 453-458.

5. Didyk, N.P. Seed pre-treatments improve resistance to allelopathic stress. Fiziol. Rast. Genet. 2017, 49, 339-346. [CrossRef] 
6. Didyk, N.P.; Zakrasov, O.V.; Rositska, N.V.; Kharitonova, I.P. Acclimation of corn plants to drought stress after a pre-treatment with allelochemicals. Fiziol. Rast. Genet. 2014, 46, 449-454.

7. Zhang, Y. Biological Role of Ascorbate in Plants. In AscorbicAcidinPlants: Biosynthesis, Regulationand Enhancement; Springer: New York, NY, USA, 2013; pp. 7-33. [CrossRef]

8. Kolupaev, Y.E.; Yastreb, T.O. Stress-protective effects of salicylic acid and its structural analogues. Physiol. Biochem. Cultiv. Plants 2013, 45, 113-126.

9. Hara, M.; Furukawa, J.; Sato, A.; Mizoguchi, T.; Miura, K. Abiotic Stress and Role of Salicylic Acid in Plants. In Abiotic Stress Responses in Plants. Metabolism, Productivity and Sustainability; Ahmad, P., Prasad, M.N.V., Eds.; Springer: New York, NY, USA, 2012; pp. 235-251.

10. Rivas-San, V.M.; Plasencia, J. Salicylic acid beyond defense: Its role in plant growth and development. J. Exp. Bot. 2011, 62, 3321-3338. [CrossRef] [PubMed]

11. Li, Z.-H.; Wang, Q.; Ruan, X.; Pan, C.-D.; Jiang, D.-A. Phenolics and Plant Allelopathy. Molecules 2010, 15, 8933-8952. [CrossRef] [PubMed]

12. Lutts, S.; Benincasa, P.; Wojtyla, L.; Kubala, S.; Pace, R.; Lechowska, K.; Quinet, M.; Garnczarska, M. Seed Priming: New Comprehensive Approaches for an Old Empirical Technique. In New Challenges in Seed Biology—Basic and Translational Research Driving Seed Technology; Araujo, S., Balestrazzi, A., Eds.; InTech: London, UK, 2016; pp. 1-49.

13. Grigoryuk, I.A.; Tkachev, V.I.; Savinski, S.V.; Musiyenko, N.N. Modern Methods of Investigations and Assessment of Drought and Heat Tolerance in Plants. Methodic Guide; Nauk. Svit: Kyiv, Ukraine, 2003; 139p.

14. Pleshkov, B.P. Practical Work on Plant Biochemistry; Agropromizdat: Moscow, Russia, 1985; 255p.

15. Komarov, M.N.; Nikolaev, L.A.; Regir, V.G.; Tesov, L.S.; Kharitonova, N.P.; Shatokhina, R.K. (Eds.) Phytochemical analysis of medicinal plants. In Methodical Guide for Laboratory Works; CPHPA: Saint Petersburg, Russia, 1998; pp. 30-35.

16. Grodzinski, A.M.; Kostroma, E.Ю.; Shrol, T.S.; Khokhlova, I.G. Methods of direct bioassay of soil and metabolites of microorganisms. In Allelopathy and Plant Productivity; Grodzinski, A.M., Golovko, E.A., Derevianko, V.A., Matveev, Y.V., Naumov, G.F., Prutenska, N.I., Yurchak, L.D., Eds.; Naukova Dumka: Kyiv, Ukraine, 1990; pp. 121-124.

17. Grodzinsky, A.M. Plant Allelopathy and Soil Sickness: Selected Works; Naukova Dumka: Kyiv, Ukraine, 1991; 432p.

18. Rinkis, G.Y.; Nollendorf, V.F. Macro and Micronutrients in Balanced Nutrition of Plants; Zinatne: Riga, Latvia, 1982; 202p.

19. Antomonov, M.Y. Mathematical Processing and Analysis of Medical and Biological Data; Publishing House "Maly Druk": Kyiv, Ukraine, 2006; 558p.

20. Alexieva, V.; Ivanov, S.; Sergiev, I.; Karanov, E. Interaction between stresses. Bulg. J. Plant Physiol. 2003, $29,1-17$.

21. Barkosky, R.R.; Einhellig, F.A. Allelopathic interference of plant-water relationships. Bot. Bull. Acad. Sin. 2003, 44, 53-58. [CrossRef]

22. Kolupaev, Y.Y.; Obozny, O.I. Active forms of oxygen and antioxidant system at cross-adaptation of plants to the action of abiotic stressors. Bull. Kharkiv Natl. Agrar. Univ. Ser. Biol. 2013, 3, 18-31.

23. Romero-Romero, T.; Sánchez-Nieto, S.; SanJuan-Badillo, A.; Cruz-Ortega, R. Comparative effects of allelochemical and water stress in roots of Lycopersicon esculentum Mill. (Solanaceae). Plant Sci. 2005, 168, 1059-1066. [CrossRef]

24. Weir, T.L.; Park, S.W.; Vivanco, J.M. Biochemical and physiological mechanisms mediated by allelochemicals. Curr. Plant Biol. 2004, 7, 472-479. [CrossRef] [PubMed]

25. Blum, U.; Gerig, T.M. Relationships between phenolic acid concentrations, transpiration, water utilization, leaf area expansion, and uptake of phenolic acids: Nutrient culture studies. J. Chem. Ecol. 2005, 31, 1907-1932. [CrossRef] [PubMed]

26. Mierziak, J.; Kostyn, K.; Kulma, A. Flavonoids as Important Molecules of Plant Interactions with the Environment. Molecules 2014, 19, 16240-16265. [CrossRef] [PubMed]

27. Fragasso, M.; Iannucci, A.; Papa, R. Durum wheat and allelopathy: Toward wheat breeding for natural weed management. Front. Plant Sci. 2013, 4, 375. [CrossRef] [PubMed]

28. Zaimenko, N.V.; Pavliuchenko, N.A.; Ellanska, N.E.; Kharytonova, I.P. The effect of drought on allelopathic, biochemical, microbiological characteristics of the system plant-soil-microorganisms. Bull. Kharkiv Natl. Agric. Univ. Ser. Biol. 2014, $286-294$.

29. Inderjit Weiner, J. Plant allelochemical interference or soil chemical ecology? Perspect. Plant Ecol. Evol. Syst. 2003, 4, 3-12. [CrossRef] 